\title{
Massa fresca de estacas e doses de ácido indolacético no enraizamento de tango ${ }^{(1)}$
}

\author{
MOISÉS ALVES MUNIZ(2), JOSÉ GERALDO BARBOSA ${ }^{(2)}$, \\ LUMA GERÇOSSIMO OLIVEIRA(2), JÉSSICA FERNANDA N. PIMENTA'(2)
}

\begin{abstract}
RESUMO
Objetivou-se com estes trabalhos avaliar doses de ácido indolacético (AIA) e a influência massa fresca de estacas no enraizamento de tango. O primeiro experimento foi montado em blocos casualizados em esquema fatorial $5 \times 3$, sendo 5 doses de AIA nas concentrações de 0, 500, 1000, 2000 e 3000 mg/L e 3 épocas de avaliação (7, 14 e 21 dias após estaqueamento) com 6 repetições. O segundo experimento foi montado também em blocos casualizados, em esquema fatorial 4 x 2, sendo 4 faixas de peso fresco $(0,5$ a 0,$7 ; 0,71$ a 0,$9 ; 0,91$ a 1,10 e maior que $1,10 \mathrm{~g})$ na presença ou ausência de ácido indolbutírico (AIB), avaliado em 2 diferentes épocas (14, 21 dias após estaqueamento-DAE) com 6 repetições. Em ambos os experimentos as estacas foram padronizadas com $5 \mathrm{~cm}$. No primeiro, experimento as estacas tiveram $1 \mathrm{~cm}$ da sua base imersa por 30 segundos, nas diferentes soluções hidroalcoólicas de AIA, enquanto no segundo a base das estacas foi imersa em água, e, posteriormente, em talco contendo $2000 \mathrm{mg} / \mathrm{kg}$, de AIB, e em seguidas colocadas para enraizar em bandejas com 256 células ( $45 \mathrm{~mL}$ ). Avaliou-se número de raízes/estaca, porcentagem de enraizamento e sobrevivência de mudas. A presença ou ausência de AIA ou AIB não interferiu na porcentagem de enraizamento das estacas e nem na sobrevivência das mudas. Não houve efeito no ciclo de enraizamento sugerindo que se utilize a dose de $2000 \mathrm{mg} / \mathrm{L}$ de AIA, pois proporcionou maior número de raízes/estaca, enquanto o aumento da massa fresca das estacas proporcionou maior número de raízes/estacas.
\end{abstract}

Palavras-chave: Solidago canadensis, hormônio, raiz, fitomassa

\begin{abstract}
Fresh weight and doses of IAA on rooting of goldenrod cuttings

The objective of this work was to evaluate the influence of indole acetic acid (IAA) on fresh weight of cuttings and in the rooting of goldenrod. The first experiment was arranged in randomized blocks in factorial scheme $5 \times 3$, and 5 doses of IAA at $0,500,1000,2000$ and $3000 \mathrm{mg} / \mathrm{L}$ and three evaluation periods $(7,14$ and 21 days after staking-DAS) with six replications. The second experiment was also established in randomized blocks in factorial scheme 4 x 2, with 4 class of fresh weight (0.5$0.7,0.71-0.9,0.91-1.10$ and greater than $1.10 \mathrm{~g}$ ) in the presence or absence of indol butyric acid (IBA) and two evaluation periods $(14,21$ days after staking), with six replications. In both experiments, the stakes were standardized to $5 \mathrm{~cm}$. In the first experiment the stakes were $1 \mathrm{~cm}$ from its base immersed for 30 seconds in different water-alcohol solutions of IAA, while the second base of the cuttings were immersed in water, and then the powder containing $2000 \mathrm{mg} / \mathrm{kg}$ of IBA, and subsequently placed for rooting in trays with 256 cells $(45 \mathrm{~mL})$. Number of roots/cutting, rooting and survival of seedlings were determined. The presence or absence of IAA or IBA does not affect the rooting of cuttings and even the survival of seedlings. There was no effect on rooting cycle suggesting that the dosage is $2000 \mathrm{mg} / \mathrm{L}$ of IAA, because it provided higher number of roots/cutting, while the increase in fresh weight of cuttings provided to increase the number of roots/cuttings.
\end{abstract}

Keywords: Solidago canadensis, hormone, root, phytomass

\section{INTRODUÇÃO}

O tango (Solidago canadensis L.), da família Asteraceae, é uma planta ornamental herbácea que, devido à beleza e durabilidade de suas inflorescências, é comercializado como flor de corte. Sua propagação é feita exclusivamente por meio de estacas apicais. Em sistemas de produção especializados, deve-se agilizar ao máximo a fase de enraizamento, uma vez que as condições ambientais controladas, normalmente empregadas nesse processo, oneram o custo de produção nessa fase.
O desenvolvimento e diferenciação de raízes na propagação de plantas por estaquia dependem de diversos fatores endógenos e exógenos, tais como características intrínsecas da espécie (balanço hormonal, teor de carboidrato, idade do tecido), tipo de estaca, ambiente de enraizamento, particularmente luz e temperatura, e presença de indutores exógenos. (CHALFUN et al., 1997, HARTMANN et al., 2002).

A capacidade de diferenciação de raízes varia entre espécies em função de a composição hormonal ser favorável ou não ao processo. Quando as condições endógenas

\footnotetext{
(1) Trabalho recebido para publicação em 13/07/2011 e aprovado em 22/10/2014

(2) Universidade Federal de Viçosa (UFV), Departamento de Fitotecnia, Universidade Federal de Viçosa, CEP 36570-000, Viçosa-MG. *Autor correspondente: jgeraldo@ufv.br.
} 
são desfavoráveis, torna-se necessária a aplicação de reguladores. Segundo Hartmann et al. (2002), aplicações exógenas de auxina proporcionam maior percentagem, velocidade, qualidade e uniformidade de enraizamento. Silveira et al. (2008), ao estudarem o enraizamento de estacas de roseira, constataram maior velocidade de diferenciação de raízes quando a concentração de AIB foi de $2000 \mathrm{mg} / \mathrm{L}$. Já Titon et al. (2003), em ensaio com o enraizamento de eucalipto, obtiveram maior velocidade de enraizamento com aplicação de 1.000 a $2.000 \mathrm{mg} / \mathrm{L}$.

Dentre os fatores da planta que interferem no enraizamento, o peso da estaca constitui-se como algo de particular importância, já que está diretamente relacionado com a quantidade de reservas, uma vez que os carboidratos são fontes de energia e de carbono para a síntese de hormônios e outras substâncias essenciais para a formação de raízes. Segundo Malavasi (1994), há relação direta entre a concentração de carboidratos e o enraizamento de estacas, uma vez que os açúcares exercem funções estruturais relevantes nos processos bioquímicos, durante a expansão celular, na formação de novos tecidos e na iniciação de raízes adventícias. Para Hartmann et al. (2002), essa relação é controversa, pois, embora a quantidade de carboidrato e o enraizamento possam estar positivamente correlacionados, os carboidratos não possuem função reguladora no enraizamento.

Quanto ao que se refere ao tango, as informações acerca da eficiência no enraizamento (quantidade, qualidade, uniformidade e velocidade) são poucas, uma vez que variáveis como tamanho, peso de estaca, uso de reguladores não foram ainda estudadas. Desta forma, este trabalho objetivou avaliar o enraizamento de tango em função da massa fresca da estaca e de doses de auxinas.

\section{MATERIAL E METODOS}

\section{Experimento 1}

Estacas apicais de tango foram colhidas de plantas matrizes do setor de Floricultura da Universidade Federal de Viçosa. Padronizadas com $5 \mathrm{~cm}$ de comprimento tiveram $1 \mathrm{~cm}$ de sua base imersa em solução hidroalcoólica de ácido indolacético (AIA) por 30 segundos, e, em seguida, colocadas para enraizar em bandejas com 256 células $(45 \mathrm{~mL})$, preenchidas com substrato comercial (Plantmax), e colocadas em câmara de nevoeiro com sombreamento de $50 \%$. Controlou-se a irrigação por meio de temporizadores acionados a cada 15 minutos, sendo de 5 segundos a duração de cada acionamento, durante o período diurno. No período noturno, entre as 22:00 e 02:00 $\mathrm{h}$, as estacas foram submetidas à iluminação artificial, com utilização de lâmpadas incandescentes $(100 \mathrm{~W})$ instaladas 1 $\mathrm{m}$ acima das estacas.

Utilizou-se o delineamento em blocos casualizados, em esquema fatorial $5 \times 3$, sendo utilizado 5 doses de AIA ( 0 , 500, 1000, 2000 e 3000 mg/L) e 3 épocas de avaliação (7, 14 e 21 dias após estaqueamento), com 6 repetições, sendo cada repetição composta por 10 estacas, totalizando 60 estacas por tratamento.

As características biométricas avaliadas foram:

- número de raízes/estaca;
- porcentagem de estacas enraizadas;

- comprimento médio de raízes;

- sobrevivência de mudas: para avaliação de sobrevivência de mudas, retiraram-se 10 estacas enraizadas dos diferentes tratamentos da câmara de nevoeiro nas diferentes épocas de avaliação, as quais foram levadas para canteiro onde se realizou o plantio em campo aberto, avaliando-se sete dias após o plantio;

\section{Experimento 2}

Estacas apicais de tango foram colhidas de plantas matrizes no setor de Floricultura da Universidade Federal de Viçosa. Padronizadas com $5 \mathrm{~cm}$ de comprimento e classificadas segundo a massa fresca. Após a classificação tiveram $1 \mathrm{~cm}$ de sua base imersa em água e, em seguida, em AIB, $2000 \mathrm{mg} / \mathrm{kg}$, na formulação de pó, e colocadas para enraizar em bandejas com 256 células $(45 \mathrm{~mL})$, preenchidas com substrato comercial (Plantmax), e colocadas em câmara de nevoeiro com sombreamento de 50\%. Controle de irrigação e luz foi semelhante ao primeiro experimento. Utilizou-se o delineamento em blocos casualizados, em esquema fatorial $4 \times 2$, sendo 4 faixas de massa fresca $(0,5-$ 0,7, 0,71-0,9, 0,91-1,10 e acima de 1,10 g), 2 concentrações de AIB (0 e $2000 \mathrm{mg} / \mathrm{kg}$ ), com avaliação em 2 épocas (14, 21 dias após estaqueamento), com 6 repetições, sendo cada repetição composta por 10 estacas, totalizando 60 estacas por tratamento. As diferentes faixas de massa foram obtidas em função do número de folhas totalmente expandidas remanescentes na estaca, sendo, 0 folha $(0,5-0,7 \mathrm{~g}), 1$ a 2 folhas $(0,71-0,9 \mathrm{~g}), 3$ a 4 folhas $(0,91-1,10 \mathrm{~g})$ e 4 a 5 folhas $(>1,10 \mathrm{~g})$.

As características biométricas foram avaliadas conforme descrito no experimento 1 .

Em experimentos os dados foram submetidos à análise de variância e regressão. Para os fatores qualitativos, as médias foram submetidas ao teste de Tukey ao nível de 5\% de probabilidade, enquanto para os fatores quantitativos, as médias foram submetidas à análise de regressão, com o auxílio do programa estatístico SAEG.

\section{RESULTADOS E DISCUSSÃO}

\section{Experimento 1}

A porcentagem de enraizamento e sobrevivência das estacas foi de $100 \%$ indicando que estas características não foram influenciadas pelas doses de AIA. Estes resultados são semelhantes aos encontrados por Lone et al. (2010), que observaram 99\% de enraizamento em estacas de azaléia independentemente da aplicação de AIB.

A análise de variância não mostrou efeito da interação época de avaliação e doses de AIB para número de raízes, sendo que, o maior número de raízes/estaca foi estimado em 25,7 na dose de 1961,4 mg/L de AIA (Figura 1). Este resultado é semelhante ao encontrado por Silveira et al. (2005) que constataram que a dose de $1960 \mathrm{mg} / \mathrm{L}$ de AIB proporcionou maior enraizamento de estacas de roseira, var. Carola, enquanto Bona et al. (2010) encontraram que a dose de $2100 \mathrm{mg} / \mathrm{kg}$ de AIB proporcionou maior número de raízes em estacas de lavandula. 


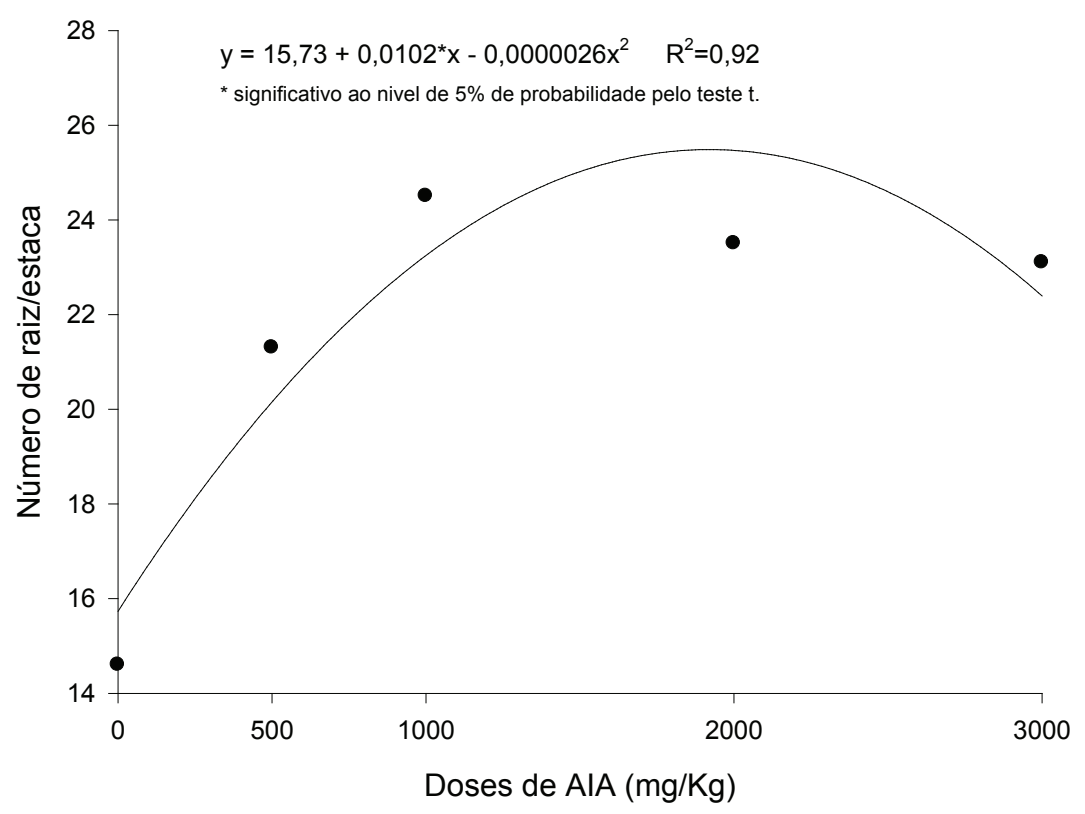

Figura 1. Número de raízes em estacas de tango submetidas a diferentes doses de AIA.

Figure 1. Number of roots in cuttings of goldenrod exposed to different doses of AIA. Viçosa-2010.

Maior número de raízes foi observado aos 21 DAE $(24,4)$ sendo superior aos 7 DAE $(14,4)$, porém não diferindo dos 14 DAE $(20,7)$ (Figura 2). Pelos resultados obtidos, pode-se recomendar que as estacas de tango sejam transferidas para o local definitivo aos 14 DAE, uma vez que já continham número satisfatório de raízes para a sobrevivência da muda.

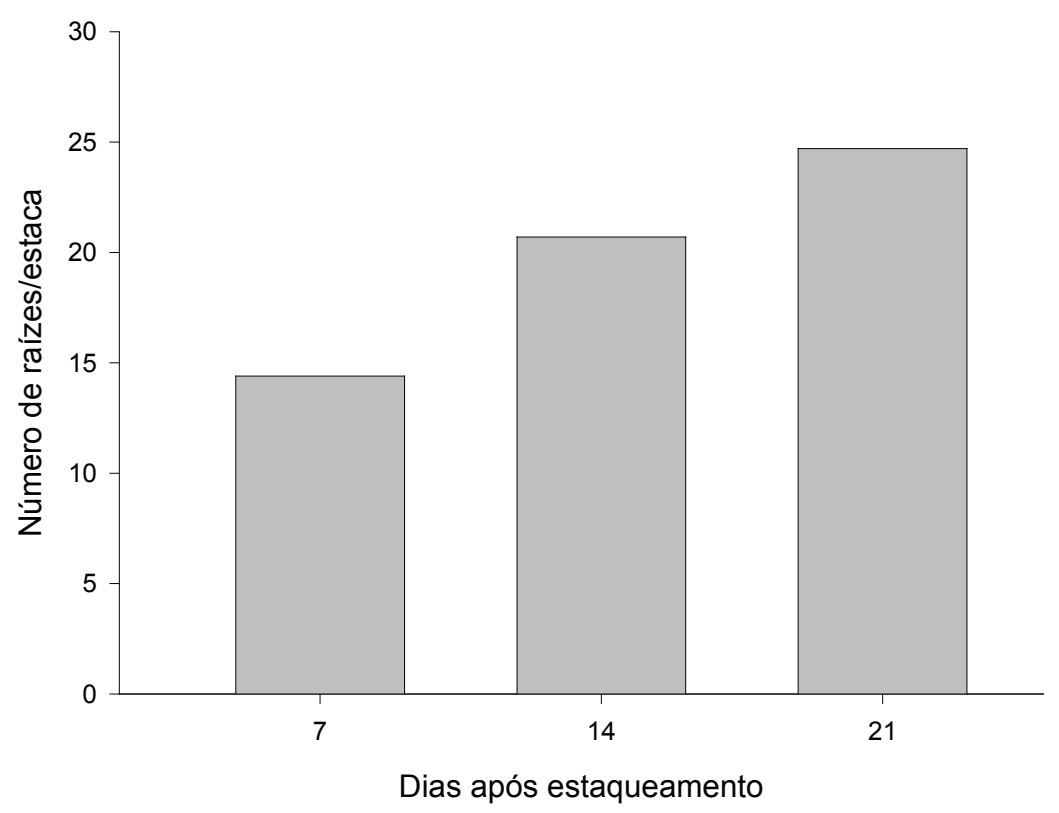

Figura 2. Número de raízes em estacas de tango em diferentes épocas de avaliação.

Médias seguidas pela mesma letra não diferem entre si ao nível de $5 \%$ de probabilidade pelo teste de Tukey.

Figure 2. Number of roots in cuttings of goldenrod at different times of evaluation. Average followed by same letter do not differ at 5\% probability by Tukey test. 
A dose de $3000 \mathrm{mg} / \mathrm{L}$ de AIA proporcionou maior comprimento da maior raiz, estimado em $6,17 \mathrm{~cm}$ (Figura 3), salienta-se que este comprimento foi superior ao comprimento da célula de enraizamento, fato não interessante, uma vez que durante a retirada da muda pode ocorrer quebra da raiz, ocasionando ferimento favorecendo o ataque de patógenos. Isto não ocorreu aos $14 \mathrm{DAE}$, período em que a maior raiz apresentava comprimento compatível com a profundidade da célula, não comprometendo a integridade do conjunto raiz mais substrato.
Houve efeito linear para doses de AIA no comprimento médio das raízes, ou seja, com o aumento da dose houve aumento do comprimento médio das raízes (Figura 3), sendo que a dose de $3000 \mathrm{mg} / \mathrm{kg}$ propiciou maior comprimento médio, estimado em $2,45 \mathrm{~cm}$. É benéfico que o sistema radicular seja o maior possível, sem que exceda o tamanho da célula, pois quanto mais extenso, maior será sua agregação com o substrato aumentando a estabilidade do bloco; além disto, ocorre maior área de absorção de água e nutrientes pela muda, favorecendo seu crescimento inicial.

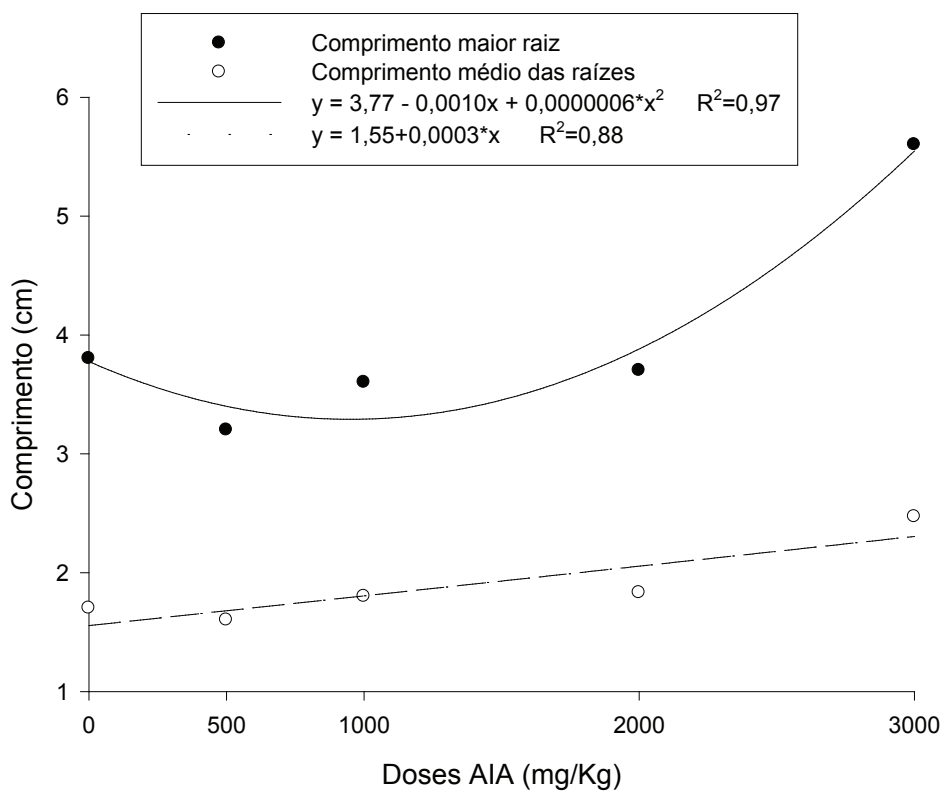

Figura 3. Comprimento da maior raiz e comprimento médio das raízes em estacas de tango submetidas a diferentes doses de AIA.

Figure 3. Length of the longest root and average length of roots in cuttings of goldenrod exposed to different doses of AIA.

\section{Experimento2}

A porcentagem de enraizamento e sobrevivência de mudas não foram afetadas pela massa fresca das estacas. Este resultado é semelhante aos observados por Zuffellato-Ribas et al. (2005) que não observaram diferença no enraizamento de estacas de Odontonema strictum em função da massa das estacas.

Entretanto, houve efeito da massa fresca no número de raiz/estaca (Figura 4). Assim, o aumento de peso fresco de estaca até a faixa $1,1 \mathrm{~g}$ resultou no maior número de raízes/estaca. O número máximo de raiz estimado foi de 12,54 com a massa fresca de 0,96 g. Pode-se explicar o aumento no número de raízes ao fato de que nas estacas com maior massa havia maior número de folhas expandidas. Estes resultados assemelham-se aos encontrados por Costa e Challa (2002), que, trabalhando com rosa, var. Madelon, observaram que o aumento da área foliar proporcionou maior número de raízes, uma vez que a principal função das folhas no processo de enraizamento é o fornecimento de carboidratos e substâncias nitrogenadas à estaca, principalmente quando estas são herbáceas. 


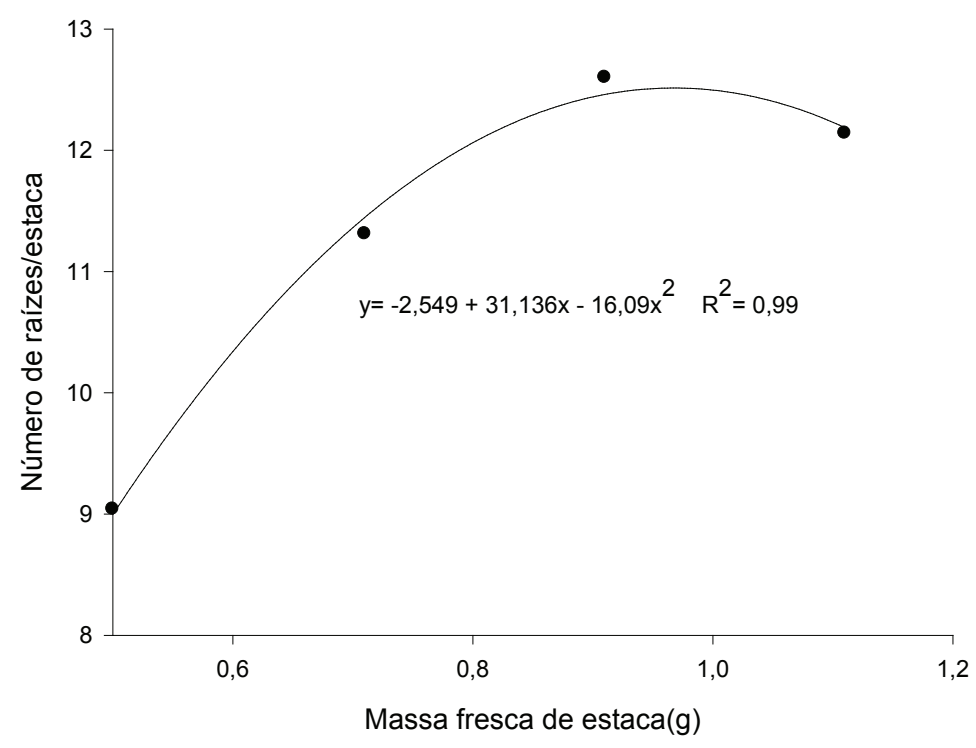

Figura 4. Número de raízes/estaca(y) em resposta a diferentes massa fresca de estacas (x) de tango.

Figure 4. Number of roots/cutting (y) in response to different fresh weight of cuttings ( $x$ ) goldenrod.

$\mathrm{O}$ uso de AIB induziu à formação de raízes mais rapidamente, em maior quantidade e com maior uniformidade (Figura 5). Observou-se que a presença de AIB $(2000 \mathrm{mg} / \mathrm{kg})$ proporcionou aumento no número de raízes em relação ao tratamento sem $\mathrm{AIB}$, com valores superiores em 63,8 e $44,7 \%$ aos 14 e aos 21 DAE, respectivamente. Estes resultados diferem dos encontrado por Lone et al. (2010) que não observaram diferença no número de raízes/estaca em azaléia na presença ou ausência de AIB (1000 mg/L). Porém, Cuquel e Minami (1994), Zuffelatto-Ribas e Rodrigues, (2001) obtiveram resultado semelhante ao constatarem maior número de raízes e maior precocidade de enraizamento em estacas de crisântemo e eucalipto tratadas com AIB, respectivamente.

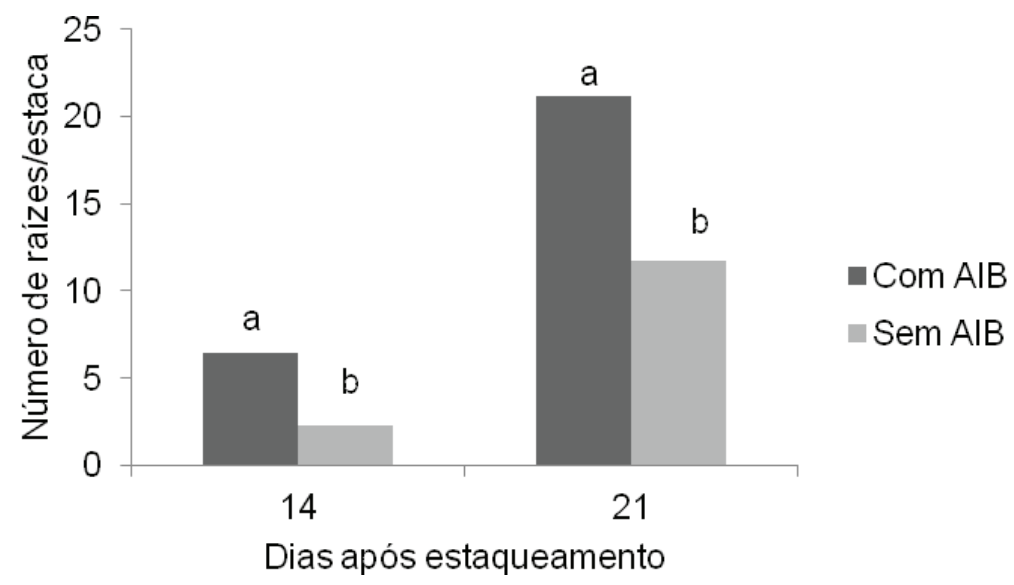

Figura 5. Número de raízes em estacas de tango com e sem AIB $(2000 \mathrm{mg} / \mathrm{kg})$ em diferentes dias após estaqueamento. Médias dentro do mesmo dia após estaqueamento seguidas pela mesma letra não diferem entre si ao nivel de $5 \%$ de probabilidade pelo teste de Tukey.

Figure 5. Number of roots in cuttings of goldenrod with and without IBA $(2000 \mathrm{mg} / \mathrm{kg})$ at different days after staking. Averages within the same day after staking followed by the same letter do not differ at $5 \%$ probability by Tukey test.

\section{CONCLUSÕES}

A presença ou ausência de AIA ou AIB não teve influencia na sobrevivência e porcentagem de estacas enraizadas, porém a dose de $2000 \mathrm{mg} / \mathrm{L}$ de AIA aumenta a velocidade de enraizamento das estacas de tango.

O maior número de raízes/estaca foi observado aos 21
DAE, mas aos 14 DAE as estacas já apresentavam número de raízes/estaca suficientes para o transplantio em local definitivo.

O aumento da massa fresca da estaca aumenta o número de raízes/estaca. A faixa de massa fresca compreendida entre 0,9 e $1,1 \mathrm{~g}$ propicia a máxima emissão de raízes por estaca com no mínimo 3 folhas. 


\section{REFERÊNCIAS}

BONA,C.M; BIASI, L.A.; LIPSKI, B; MASETTO, M.A.M.; DESCHAMPS, C. Enraizamento adventício de estacas de Lavandula dentata tratadas com auxina. Ciencia Rural, v.40, n.5, p.1210-1213, 2010.

CHALFUN, N.N.J.; HOFFMANN, A.; CHALFUN, A.J.; JESUS, A.M. dos S. Efeito da auxina e do anelamento no enraizamento de estacas semilenhosas de azaléias. Ciência e Agrotecnologia, v.21, n.4, p.516-520, 1997.

COSTA, J.M., CALLA, H. The effect of the original leaf area on growth of softwood cuttings and planting material of rose. Scientia Horticulturae v.95, p.111-121, 2002.

CUQUEL, F.L., MINAMI, K. Enraizamento de estacas de crisântemo (Dendranthema morífolium (Ramat.) Tzvelev) tratadas com acido indolbutírico veiculado em talco. Scientia Agricola, v.51, n.1, p.28-35, 1994.

HARTMANN, H.T; KESTER D.E.; DAVIES Jr, F.T., GENEVE, R.L. Plant Propagation: Principles and Practice. 7ed. New Jersey. Prentice-Hall, 2002. 770p.

LONE, A.B.; UNEMOTO, L.K.; YAMAMOTO, L.Y.; COSTA, L, et al. Enraizamento de estacas de azaleia (Rhododendron simsii Planch.) no outono em AIB e diferentes substratos. Ciência Rural, v.40, n.8, p.1720-1725, 2010.
MALAVASI, U.C. Macropropagação vegetativa em coníferas: perspectivas biológicas e operacionais. Floresta e Ambiente. n.1, p.131-135, 1994.

SILVEIRA, J.Q; FILHO, J.A.; SIMANCA, J.C.; SALES, G.M.; MOTA, J.C.A. Efeito de concentrações de acido indolbutirico no enraizamento de estacas de roseiras Rosa sp das variedades Carola e Salmone. Disponível em: <http://www.sbpcnet.org.br/livro/57ra/ programas/senior/RESUMOS/resumo_2595.html> Acesso em: 09/06/2011

TITON, M.; XAVIER, A.; OTONI, W.C.; REIS, G.G. Efeito do AIB no enraizamento de miniestacas e microestacas de clones de Eucaliptus grandis W. Hill Maiden. Revista Árvore, v.27, n.1, p. 1-7, 2003.

ZUFFELATO-RIBAS, K.C.; RODRIGUES, J.D. Relações entre épocas do ano e diferentes concentrações de acido indol-butiríco no enraizamento de estacas de Eucalyptus grandis. Boletim de Pesquisa Florestal. n.42, p.61-70., 2001.

ZUFFELLATO-RIBAS, K.C; BOEGER, M.R.T; BONA, C; PAES, E.G.B; PIMENTA, A.C; MASUDA, E.T. Enraizamento e morfo-anatomia de estacas caulinares de -Odontonema strictum kuntze (Acanthaceae). Revista Brasileira de Horticultura Ornamental, v.11, n.1, p.67$61,2005$. 